\title{
Práticas Pedagógicas Colaborativas utilizando Ferramentas Digitais: Um Relato de experiência na formação de educadores
}

\author{
Fernando Lucas de Oliveira Farias, Everton da Silva Brito, Elvis Medeiros de Melo, Laís \\ Michelle de Souza Araújo Bandeira, Felipe Jhonanta Ferreira da Costa, Igo Joventino \\ Dantas Diniz, Sidney Soares Trindade, Isabel Dillmann Nunes
}

Instituto Metrópole Digital - Universidade Federal do Rio Grande do Norte (UFRN) Av. Sen. Salgado Filho, 3000 - Lagoa Nova, CEP: 59.078-970 - Natal - RN - Brasil

\{fernandoo.mcp, evertondsb36, elvismedeiros.mm, bandeiralaism, felipejfc, igojoven\} egmail.com, sidneyeinfo.ufrn.br, beleimd.ufrn.br

Abstract. With the emergence of new technologies and appropriation of these tools in students' daily lives, it is necessary to use such resources in teaching. This article presents the results obtained during an experience in the workshop "Collaborative Pedagogical Practices in build the Professional Skills of the Future" workshop with teachers of basic education. Whose objective was to present digital tools to support collaborative pedagogical practices, production of questionnaires and interactive polls, as well as a collaborative environment. The analyzes carried out indicate changes in the teachers' perception of collaboration, the use of the TDICs in the classroom and their greater commitment to changes in their teacher praxis as a result of the knowledge acquired in workshop.

Resumo. Com o surgimento de novas tecnologias e apropriação dessas ferramentas no cotidiano dos estudantes, faz-se necessário o uso de tais recursos no ensino. Este artigo apresenta os resultados obtidos durante uma experiência na oficina "Práticas Pedagógicas Colaborativas na formação das habilidades do profissional do futuro" realizada com professores da educação básica. O objetivo foi apresentar ferramentas digitais de apoio a práticas pedagógicas colaborativas, produção de questionários e enquetes interativas, assim como uso de ambiente colaborativo gamificado. As análises realizadas indicam mudanças na percepção dos educadores sobre colaboração, uso das TDICs em sala de aula e seu maior engajamento para mudanças em suas práxis docente, fruto dos conhecimentos adquiridos na oficina.

\section{Introdução}

$\mathrm{O}$ uso de ferramentas digitais em sala de aula tem se intensificado, principalmente pela necessidade de incorporação de metodologias ativas de ensino que coloquem o estudante como sujeito ativo dos processos de ensino e aprendizagem [Diesel, Baldez e Martins 2017]. Um dos desafios paralelos à isso é a necessidade da apropriação dessas ferramentas nas rotinas de sala de aula, de forma a proporcionar práticas pedagógicas personalizadas, lúdicas, inovadoras e cada vez mais colaborativas, alinhadas com os objetivos de aprendizagem e sequências didáticas inerentes à prática docente. 
VII Congresso Brasileiro de Informática na Educação (CBIE 2018)

Anais do XXIV Workshop de Informática na Escola (WIE 2018)

Segundo Antunes e Barroso (2015), o uso da tecnologia como ferramenta de ensino pode auxiliar no processo educacional, tanto para alunos, professores e gestores. Contudo, as consequências (positivas e negativas) provenientes da aplicação da tecnologia no âmbito educacional dependerá de seu uso perante as rotinas de trabalho.

A utilização de recursos tecnológicos como ferramentas didáticas na escola já pode ser considerada uma realidade no Brasil e no mundo. Projetos de inclusão digital na escola com aquisição de projetores, tablets, lousas digitais e implantação de laboratórios de informática com acesso à internet, são exemplos de iniciativas existentes que permitem aprimorar os processos de ensino e aprendizagem com o apoio da tecnologia, seja no ensino básico, técnico ou tecnológico [Oliveira et al. 2017].

Neste contexto, o presente trabalho tem como objetivo apresentar um relato de experiência envolvendo uma oficina intitulada "Práticas Pedagógicas Colaborativas utilizando Ferramentas Digitais na formação das habilidades do profissional do futuro" para professores da educação básica, alunos do último período do curso de Licenciatura em Pedagogia do Instituto de Educação Superior Presidente Kennedy - IFESP ofertada por mestrandos do Programa de Pós-graduação em Inovação em Tecnologias Educacionais - PPgITE do IMD/UFRN.

O curso seguiu o aspecto sugerido por Beira e Nakamoto (2016). Eles sugerem que a formação docente deve proporcionar condições necessárias para que os professores dominem tais ferramentas, superando abordagens triviais de metodologias ativas de ensino e do conhecimento sistemático dos processos de ensino e aprendizagem. Na oficina proposta, os participantes consideraram significativa a aprendizagem colaborativa com uso das tecnologias propostas.

Este trabalho está organizado da seguinte forma: além desta introdução, na Seção 2 são apresentados estudos relacionados à formação de professores e legislação correlata; a Seção 3 apresenta a metodologia utilizada; a Seção 4 apresenta os resultados obtidos com a oficina; a Seção 5 detalha a avaliação dos participantes coletada na avaliação de reação; a Seção 6 apresenta as Lições Aprendidas durante o estudo e por fim, a Seção 7 detalha as Considerações Finais e apresenta possibilidades para Trabalhos Futuros.

\section{Formação de Professores para as TDICs}

Sobre a formação docente, inicial e continuada; temos como base a Lei de Diretrizes e Bases da Educação Nacional, Lei $n^{0}$ 9.394/96, que em seu art. 61 estabelece que a formação de profissionais de educação, de modo a atender os objetivos dos diferentes níveis e modalidades de ensino e as características de cada fase do desenvolvimento do educando, terá como fundamento a associação entre a teoria e a prática mediante a capacitação em serviço e o aproveitamento da formação e experiências anteriores em instituições de ensino e outras atividades, enquanto o art. 67 da mesma lei disciplina que os sistemas de ensino deverão valorizar os profissionais da educação, assegurando inclusive, o aperfeiçoamento profissional [Beira e Nakamoto 2016].

Segundo Procópio (2011), a formação de professores através das tecnologias digitais proporciona o desenvolvimento profissional e ascensão em sua qualificação acadêmica, contribuindo inclusive para prática escolar nos mais diversos níveis de ensino. Sendo que tais tecnologias estão cada vez mais presentes em nosso cotidiano, exigindo mudanças nas habilidades e estratégias didáticas por parte do professor. 
VII Congresso Brasileiro de Informática na Educação (CBIE 2018)

Anais do XXIV Workshop de Informática na Escola (WIE 2018)

Vasconcelos et al. (2016), apresentam o planejamento e realização de uma oficina de capacitação de professores em escolas públicas do estado da Paraíba para a inclusão do tablet educacional em sala de aula. Os resultados da atividade demonstraram que apesar das dificuldades dos professores em utilizar os tablets, o desejo de aprender e de proporcionar aos alunos novas práticas pedagógicas foi fundamental para o seu progresso na oficina; principalmente pelo processo inicial de reflexão sobre o porquê e o para quê utilizar os tablets em sala de aula. A apresentação de experiências exitosas da utilização desses tablets em outras unidades, contribuíram para despertar nos professores o desejo de saber como utilizar o tablet educacional em suas aulas, proporcionando uma experiência motivadora.

Silva e Filho (2016), descrevem o processo de formação de professores do Ensino Fundamental de uma escola contemplada pelo Projeto Um Computador por Aluno (UCA), ofertada com objetivo de trabalhar a aprendizagem colaborativa em rede utilizando o laptop educacional. Os resultados indicam a predisposição dos professores em conhecer ferramentas digitais que favorecessem a aprendizagem colaborativa e os auxiliassem no incremento de suas aulas, sendo identificado empenho no desenvolvimento das atividades propostas durante a formação e interesse na utilização dos conhecimentos construídos em sua prática pedagógica.

Neste sentido, a oficina proposta buscou alinhar conhecimento didático, técnico e tecnológico, a fim de proporcionar mudanças nas práticas pedagógicas dos participantes, evidenciadas pela maior utilização de ferramentas digitais e práticas pedagógicas colaborativas, em sintonia com metodologias ativas de ensino.

\section{Metodologia}

Utilizou-se como metodologia para desenvolvimento dos trabalhos a pesquisa-ação. Delimitouse o problema da pesquisa relacionando-o ao uso de ferramentas digitais em práticas pedagógicas colaborativas e identificação do nível de conhecimento acerca dos recursos digitais a serem trabalhados com os participantes da oficina. Promoveu-se uma ação perante os participantes e foram analisados os resultados desta ação.

Segundo Thiollent (2011) a pesquisa-ação é um tipo de pesquisa social de base empírica, idealizada e conduzida em estreita relação com uma ação ou resolução de problemas dentro de uma atividade em que os pesquisadores e os participantes estão envolvidos em modo cooperativo ou participativo, neste sentido, o planejamento da oficina seguiu as fases detalhadas na Tabela 1.

A oficina ocorreu no dia vinte e nove de maio de dois mil e dezoito, com carga horária total de 3 (três) horas e participação de quinze professores da Educação Básica de diversas instituições de Ensino do Rio Grande do Norte.

A oficina foi ministrada em 3 etapas: i) explanação inicial sobre a Escola 3.0, perfil do Educador 3.0, educação baseada em portfólio x 10 Top Habilidades para profissional do futuro; ii) apresentação e demonstração de ferramentas digitais para práticas pedagógicas colaborativas; e, por fim, iii) disponibilização de links para portais com ferramentas digitais, objetos de aprendizagem e material multimídia para apoio na utilização das TDICs em sala de aula, conforme Tabela 3. 
VII Congresso Brasileiro de Informática na Educação (CBIE 2018)

Anais do XXIV Workshop de Informática na Escola (WIE 2018)

Tabela 1. Planejamento da Oficina

\begin{tabular}{|c|c|}
\hline Fase & Descrição \\
\hline $\begin{array}{l}\text { Levantamento } \\
\text { bibliográfico }\end{array}$ & $\begin{array}{l}\text { Levantamento bibliográfico relacionado aos principais conceitos da Escola } 3.0 \text { e o Perfil do } \\
\text { Educador 3.0, } 10 \text { Top Habilidades para profissional do futuro, práticas pedagógicas } \\
\text { colaborativas utilizando ferramentas digitais e pesquisas que abordassem relatos de experiências } \\
\text { na formação de professores para uso das Tecnologias Digitais da Informação e Comunicação } \\
\text { (TDICs) em sala de aula. }\end{array}$ \\
\hline $\begin{array}{l}\text { Modelagem } \\
\text { Mapa Mental }\end{array}$ & $\begin{array}{l}\text { Nesta fase, foi elaborado colaborativamente utilizando a ferramenta Coggle um mapa mental }{ }^{1} \\
\text { ilustrando as principais etapas do planejamento, execução e avaliação da oficina. }\end{array}$ \\
\hline $\begin{array}{l}\text { Planejamento } \\
\text { da oficina }\end{array}$ & $\begin{array}{l}\text { Foram definidos o objetivo geral, conteúdos, metodologia, recursos necessários, instrumentos de } \\
\text { avaliação e resultados esperados com a oficina; bem como elaboração das atividades } \\
\text { relacionadas ao aprendizado das ferramentas digitais: 1- Mentimeter, } 2 \text { - Google Forms, } 3 \text { - } \\
\text { Google Docs, } 4 \text { - Coggle, } 5 \text { - Plickers e } 6 \text { - Classdojo; os slides }{ }^{2} \text { utilizados durante a atividade e } \\
\text { as práticas pedagógicas colaborativas apoiadas pelas ferramentas digitais supra. }\end{array}$ \\
\hline $\begin{array}{l}\text { Diagnóstico } \\
\text { inicial }\end{array}$ & $\begin{array}{l}\text { Utilizou-se um Survey }{ }^{3} \text { para colher informações inerentes ao diagnóstico do perfil dos } \\
\text { participantes da Oficina "Práticas Pedagógicas Colaborativas para formação das habilidades do } \\
\text { profissional do futuro", bem como identificar o nível de conhecimento destes nas seguintes } \\
\text { temáticas: } 1 \text { - Ferramentas interativas de apoio a práticas pedagógicas colaborativas, } 2 \text { - } \\
\text { Metodologias Ativas de Ensino, } 3 \text { - Principais habilidades para os profissionais do futuro, } 4 \text { - } \\
\text { Escola } 3.0 \text { e o Perfil do Educador } 3.0 \text { e } 5 \text { - Benefícios da utilização de ambientes e sistemas } \\
\text { colaborativos para Educação". }\end{array}$ \\
\hline $\begin{array}{l}\text { Execução da } \\
\text { oficina }\end{array}$ & $\begin{array}{l}\text { A execução da oficina teve como objetivo permitir aos participantes conhecer ferramentas } \\
\text { digitais de apoio a práticas educacionais colaborativas, produção de questionários e enquetes } \\
\text { interativas, bem como reflexão sobre as habilidades para profissionais do futuro propostas pelo } \\
\text { Fórum Econômico Mundial. }\end{array}$ \\
\hline $\begin{array}{l}\text { Avaliação de } \\
\text { reação }\end{array}$ & $\begin{array}{l}\text { Ao final da oficina foi aplicado um novo Survey para avaliação da oficina "Práticas } \\
\text { Pedagógicas Colaborativas para formação das habilidades do profissional do futuro" por parte } \\
\text { dos participantes, bem como avaliar a mudança de sua percepção em relação aos aspectos } \\
\text { avaliados no Diagnóstico inicial. Os resultados obtidos foram analisados. }\end{array}$ \\
\hline
\end{tabular}

\subsection{Explanação inicial}

Na explanação inicial foram apresentados os principais conceitos relacionados a Educação 1.0 até a 3.0, exibição do vídeo "Conhecendo o Perfil do Educador 3.0"5 desenvolvido pelos mestrandos do Programa de Inovação em Tecnologias Educacionais - PPgITE do IMD/UFRN; as características do Professor 3.0: Tendências, cenários e consequências; aprendizagem significativa; habilidades e estratégias didáticas; desenvolvimento integral; atitude de explorador; continuar ativamente aprendendo; esforços coletivos para melhorar a educação; olhar voltado para o aprendizado de seus alunos; contato direto com os estudantes; compartilhar sua paixão com outros; Faz a diferença.

\footnotetext{
${ }^{1}$ Disponível em: "http://bit.ly/2JujHM5"

2 Disponível em: "http://bit.ly/2JgK4Im"

3 Disponível em: "http://bit.ly/2sfvcQZ"

4 Disponível em: "http://bit.ly/2kxAMde"

${ }^{5}$ Disponível em: < https://www.youtube.com/watch?v=r6DRhTklMZA>. Acesso em: 12 jun. 2018.
} 
Em seguida, a introdução foi encerrada com a contextualização dos principais avanços da Inteligência Artificial apresentados no vídeo ${ }^{6}$ produzido pelo programa "Expresso Futuro" do Canal Futura e as 10 Top habilidades para o profissional do futuro até 2020 propostas pelo Fórum Econômico Mundial.

\subsection{Ferramentas Digitais para Práticas Pedagógicas Colaborativas}

Após a explanação inicial, foram apresentados aos educadores as ferramentas digitais a serem trabalhadas na oficina (Mentimeter, Google Forms, Google Docs, Coggle, Plickers e Classdojo), com suas definições, principais funcionalidades, aspectos colaborativos, formas de acesso e aplicabilidade pedagógica nos processos de ensino e aprendizagem, conforme Tabela 2.

\section{Tabela 2. Ferramentas Digitais para apoio a Práticas Pedagógicas Colaborativas}

\begin{tabular}{|c|c|}
\hline $\begin{array}{c}\text { Ferramenta } \\
\text { Digital }\end{array}$ & Como Utilizar em Sala de Aula \\
\hline Mentimeter & $\begin{array}{l}\text { O Mentimeter é um sistema para criação de enquetes interativas, que permite aos usuários a } \\
\text { criação em poucos minutos, de maneira gratuita e sem necessidade de registros. Para isso basta } \\
\text { somente configurar a pergunta que deseja vincular a enquete para posteriormente customizar as } \\
\text { opções em que os usuários poderão votar. Ela é útil na etapa de descoberta e brainstorming } \\
\text { comuns no Design Thinking. }\end{array}$ \\
\hline Google Docs ${ }^{7}$ & $\begin{array}{l}\text { O Google Docs é uma ferramenta de colaboração online, que permite o acesso, criação e } \\
\text { edição dos seus documentos em qualquer dispositivo, incluindo seu smartphone, tablet ou } \\
\text { computador em qualquer lugar, mesmo sem conexão com a internet. A partir do Google Docs, } \\
\text { todos podem trabalhar simultaneamente no mesmo documento, compartilhar com qualquer } \\
\text { pessoa, acessar recursos de chat e comentários, constituindo em importante ferramenta digital } \\
\text { no apoio às práticas pedagógicas colaborativas em sala de aula. }\end{array}$ \\
\hline Google Forms ${ }^{8}$ & $\begin{array}{l}\text { O Google Forms é uma poderosa ferramenta para criação e edição colaborativa de formulários, } \\
\text { permitindo que você colete respostas rapidamente, configure perguntas e respostas } \\
\text { personalizadas, incluindo a escolha entre várias opções de perguntas, de múltipla escolha a } \\
\text { listas suspensas e escalas lineares; adição de vídeo do Youtube e navegação por páginas e } \\
\text { lógica de ramificação de perguntas.As respostas são coletadas automaticamente gerando } \\
\text { informações e gráficos em tempo real, tanto em planilha ou dashboard na Web, transformando } \\
\text { a experiência com seus aprendizes em sala de aula. }\end{array}$ \\
\hline Coggle $^{9}$ & $\begin{array}{l}\text { O Coggle procura disponibilizar de forma clara e intuitiva, recursos que permitem você gerar e } \\
\text { compreender informações complexas através de mapas mentais, sendo seu grande diferencial a } \\
\text { possibilidade de construção e edição colaborativa de mapas mentais, alterando a forma como } \\
\text { seus alunos trabalham e colaboram em sala de aula. }\end{array}$ \\
\hline Plickers $^{10}$ & $\begin{array}{l}\text { Plickers é uma simples, intuitiva e poderosa ferramenta que auxilia os professores na coleta de } \\
\text { dados em tempo real durante avaliação formativa, sem a necessidade de dispositivos dos } \\
\text { alunos. Utilizando seu smartphone, o professor através da câmera coleta instantaneamente as } \\
\text { respostas dos estudantes mediante a leitura de cartões especialmente codificados exibidos por } \\
\text { eles, assegurando verificações rápidas para entender e acompanhar a evolução da } \\
\text { aprendizagem de seus aprendizes, provendo feedback instantâneo durante o processo. }\end{array}$ \\
\hline
\end{tabular}

\footnotetext{
${ }^{6}$ Disponível em: $<$ https://www.youtube.com/watch?v=CM5_epaUje8 $>$. Acesso em: 12 jun. 2018.

${ }^{7}$ Disponível em: $<$ https://www.google.com/intl/pt-BR/docs/about/>. Acesso em: 12 jun. 2018

${ }^{8}$ Disponível em: $<$ https://www.google.com/intl/pt-BR/forms/about/>. Acesso em: 12 jun. 2018

${ }^{9}$ Disponível em: <"https://coggle.it>. Acesso em: 12 jun. 2018

${ }^{10}$ Disponível em: <https://www.plickers.com/>. Acesso em: 12 jun. 2018
} 
VII Congresso Brasileiro de Informática na Educação (CBIE 2018)

Anais do XXIV Workshop de Informática na Escola (WIE 2018)

\begin{tabular}{|c|l|}
\hline $\begin{array}{c}\text { Ferramenta } \\
\text { Digital }\end{array}$ & \multicolumn{1}{c|}{ Como Utilizar em Sala de Aula } \\
\hline Classdojo $^{11}$ & $\begin{array}{l}\text { O Classdojo é uma plataforma online que permite conectar professores, alunos e pais para } \\
\text { construção de salas de aula divertidas, integradas e empolgantes; criando uma cultura positiva } \\
\text { que busca incentivar os alunos no desenvolvimento colaborativo de suas habilidades, } \\
\text { compartilhando seu aprendizado através da publicação de fotos e vídeos do seu portfólio na } \\
\text { plataforma que está disponível para iOS, Android, Kindle Fire e em qualquer computador } \\
\text { respeitando rigorosos requisitos de privacidade. }\end{array}$ \\
\hline
\end{tabular}

\subsection{Material de apoio para uso das TDICs em Sala de Aula}

Após a apresentação das ferramentas digitais para práticas pedagógicas colaborativas, foram disponibilizados, ao final da oficina, diversos links para portais e repositórios virtuais de ferramentas digitais, objetos de aprendizagem e materiais multimídia que podem servir de apoio à inserção das TDICs em sala de aula; sendo que alguns dos materiais disponibilizados são descritos na Tabela 3.

Tabela 3. Materiais de apoio ao uso das TICs em Sala de Aula

\begin{tabular}{|c|c|c|}
\hline Referência & Descrição & Link \\
\hline Portal "Co-Laborando" & $\begin{array}{l}\text { O Co-Laborando foi elaborado por professores para } \\
\text { professores. Neste portal, é possível encontrar slides, } \\
\text { tutoriais, vídeo-aulas, ferramentas digitais, planos de aula } \\
\text { sobre os mais diversos conteúdos curriculares, incluindo: } \\
\text { Língua Portuguesa, História, Ciências, Arte, Matemática, } \\
\text { Geografia, Língua Inglesa e Temas Integradores; bem } \\
\text { como conteúdos relacionados a Ferramentas Digitais, } \\
\text { Formação Docente, Educação Especial, Eventos, } \\
\text { Aprendizagem Criativa, entre outros. }\end{array}$ & $\begin{array}{l}\text { https://www.colaborando.net. } \\
\text { br/ }\end{array}$ \\
\hline $\begin{array}{l}\text { Portal "Escola na } \\
\text { Rede" }\end{array}$ & $\begin{array}{l}\text { A plataforma tem como uma de suas finalidades, } \\
\text { possibilitar o acesso de professores, gestores, estudantes, } \\
\text { demais segmentos de ensino e comunidade aos Objetos } \\
\text { Digitais de Aprendizagem (ODA) e outros recursos } \\
\text { pedagógicos disponíveis na plataforma Escola na Rede. }\end{array}$ & $\begin{array}{c}\text { http://www.escolasnarede.see } \\
\text { c.rn.gov.br/ }\end{array}$ \\
\hline $\begin{array}{l}\text { Repositório de Objetos } \\
\text { de Aprendizagem para } \\
\text { Matemática "Obama" }\end{array}$ & $\begin{array}{l}\text { Tem como proposta disponibilizar aos professores de } \\
\text { matemática da Educação Básica um ambiente com maior } \\
\text { número de Objetos de Aprendizagem (OAs) para as suas } \\
\text { aulas; com a indicação da etapa de ensino, tema } \\
\text { curricular e a confiabilidade das características } \\
\text { pedagógicas do recurso, inclusive planos de aula com os } \\
\text { OAs. }\end{array}$ & https://obama.imd.ufrn.br/ \\
\hline $\begin{array}{l}\text { Treinamentos } \\
\text { "Google For } \\
\text { Education" }\end{array}$ & $\begin{array}{l}\text { Plataforma de treinamentos disponibilizada pelo Google } \\
\text { para que educadores possam conhecer melhor as } \\
\text { ferramentas digitais do G Suite for Education a exemplo } \\
\text { do Gmail, Docs, Planilhas, Apresentações, Sala de Aula } \\
\text { e demais ferramentas para que possam engajar seus } \\
\text { alunos a qualquer hora, em qualquer lugar através de } \\
\text { estratégias inovadoras de sua integração na sala de aula. }\end{array}$ & $\begin{array}{l}\text { https://edutrainingcenter.with } \\
\text { google.com/training }\end{array}$ \\
\hline
\end{tabular}

${ }^{11}$ Disponível em: <https://www.classdojo.com/pt-br/>. Acesso em: 12 jun. 2018 
VII Congresso Brasileiro de Informática na Educação (CBIE 2018)

Anais do XXIV Workshop de Informática na Escola (WIE 2018)

\begin{tabular}{|c|c|c|}
\hline Referência & Descrição & Link \\
\hline Portal "KhanAcademy" & $\begin{array}{l}\text { A Khan Academy oferece exercícios, vídeos de instrução } \\
\text { e um painel de aprendizado personalizado que habilita os } \\
\text { estudantes a aprender no seu próprio ritmo dentro e fora } \\
\text { da sala de aula. Sendo que alguns conteúdos } \\
\text { especializados são produzidos em parceria com a NASA, } \\
\text { o Museu de Arte Moderna, Academia de Ciências da } \\
\text { Califórnia e o MIT. A missão da plataforma é } \\
\text { proporcionar uma educação gratuita e de alta qualidade } \\
\text { para todos, em qualquer lugar. }\end{array}$ & https://pt.khanacademy.org/ \\
\hline Projeto “Programaê!" & $\begin{array}{l}\text { Um portal prático e agregador de ideias, soluções e dicas } \\
\text { criadas por colaboradores experientes e inspiradores, } \\
\text { criando um movimento que quer aproximar a } \\
\text { programação do cotidiano de jovens de todo o Brasil, } \\
\text { tem como parceiros o Scratch, Codecademy, MIT App } \\
\text { Inventor, KhanAcademy, Stembyme, URI Online Judge, } \\
\text { entre outros. }\end{array}$ & http://programae.org.br/ \\
\hline
\end{tabular}

\subsection{Avaliação}

A avaliação de reação realizada com os participantes da oficina ao término da atividade, teve como objetivo identificar mudanças de sua percepção quanto aos benefícios da utilização de ferramentas digitais no apoio a práticas pedagógicas colaborativas e seu engajamento para mudança de atitudes em sua práxis docente com base nos conhecimentos e habilidades trabalhados durante a oficina. Neste sentido, identificamos que $75 \%$ classificaram como "5 Extremamente importante" a aplicação de práticas pedagógicas colaborativas nos processos de ensino e aprendizagem, enquanto no início da oficina na fase de diagnóstico apenas $30 \%$ tinham essa percepção.

Enquanto a vontade de mudar suas atitudes, baseado no que aprendeu durante a oficina numa escala de 1 - Pouca a 5 - Muito Forte; $25 \%$ assinalaram como 4 e $75 \%$ assinalaram como 5. Por conseguinte, no que diz respeito ao grau de satisfação geral quanto aos resultados da oficina numa escala de 1 - Pouco Satisfeito a 10 - Muito Satisfeito, 50\% dos participantes assinalaram como $8,25 \%$ como 9 e $25 \%$ como 10 . Não obstante, tais dados permitem concluir a mudança significativa da percepção dos participantes quanto a importância da aprendizagem colaborativa, bem como elevado índice de satisfação quanto às atividades desenvolvidas durante a oficina e relevância das ferramentas digitais apresentadas.

\section{Resultados}

Na fase de diagnóstico, visando conhecer o perfil dos participantes da oficina foi utilizada a metodologia do Design Thinking [Vianna et al. 2012] apoiada pela ferramenta digital Mentimeter $^{12}$ na qual, utilizando seus dispositivos móveis, os docentes compartilharam suas expectativas sobre a oficina ${ }^{13}$, percepção sobre os desafios da sala de aula no século $\mathrm{XXI}^{14} \mathrm{e}$ quais metodologias ativas de ensino conheciam ${ }^{15}$.

\footnotetext{
12 Disponível em: <https://www.mentimeter.com/>. Acesso em: 12 jun. 2018

${ }^{13}$ Disponível em "http://bit.ly/2McXeET"

${ }^{14}$ Disponível em "http://bit.ly/2HwClRE"

15 Disponível em "http://bit.ly/2JEYKBi"
} 
VII Congresso Brasileiro de Informática na Educação (CBIE 2018)

Anais do XXIV Workshop de Informática na Escola (WIE 2018)

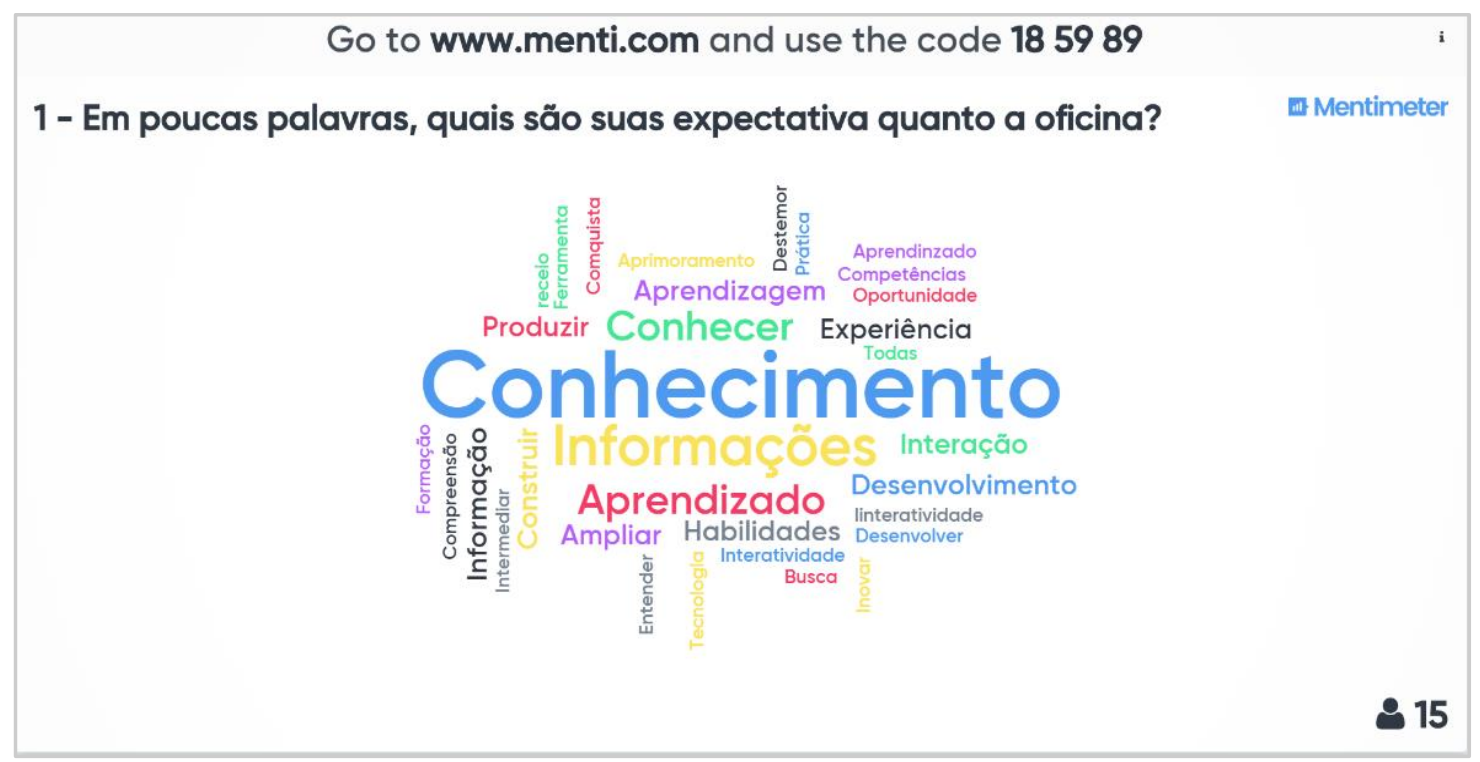

Figura 1. Expectativas dos participantes da oficina coletadas com Mentimeter

Quanto ao nível de conhecimento dos participantes acerca das ferramentas digitais trabalhadas durante a oficina, identificamos que $80 \%$ não conheciam o Mentimeter, $70 \%$ não conheciam o Google Forms, $10 \%$ não conheciam o Google Docs, $60 \%$ não conheciam o Coggle, $80 \%$ não conheciam o Plickers e $90 \%$ não conheciam o Classdojo conforme Figura 2, partindo destes dados a oficina priorizou as ferramentas $1,4,5$ e 6 .

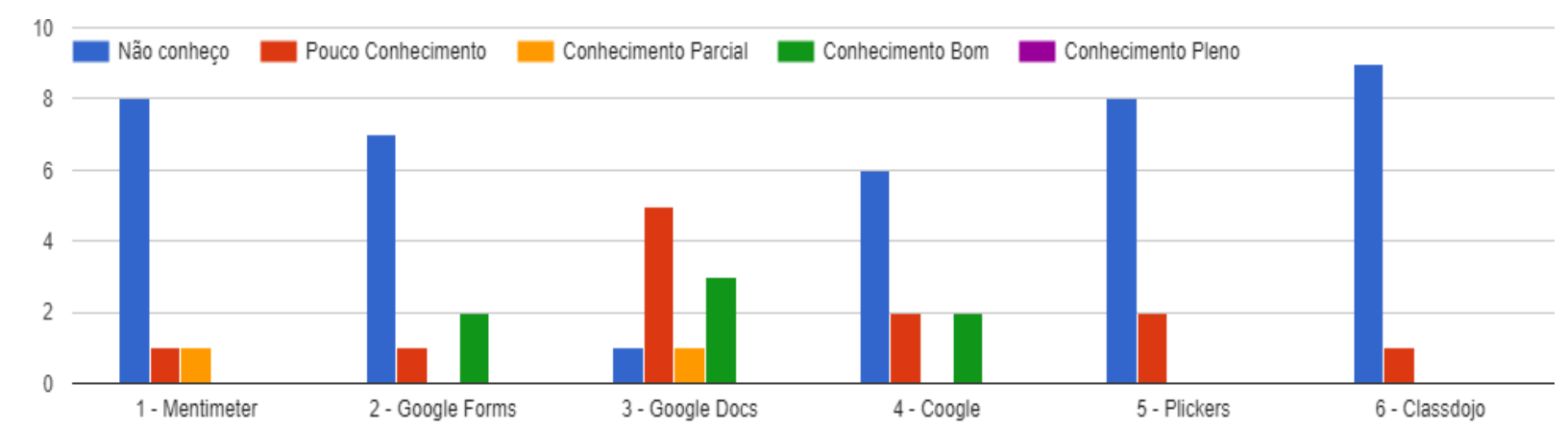

Figura 2. Nível de Conhecimento das ferramentas dos participantes da oficina na fase diagnóstico

Outro aspecto avaliado na fase de diagnóstico foi a percepção dos participantes da oficina acerca da importância da aprendizagem colaborativa ou aplicação de técnicas de práticas pedagógicas colaborativas nos processos de ensino e aprendizagem numa escala de 1 - Nem um pouco importante a 5 - Extremamente importante; uma vez que um dos propósitos da oficina foi oportunizar o conhecimento de ferramentas digitais de apoio às práticas pedagógicas colaborativas. Neste sentido, $20 \%$ dos participantes julgam como 1 - Nem um pouco importante e $30 \%$ como 5 - Extremamente importante, conforme ilustrado na Figura 3. 


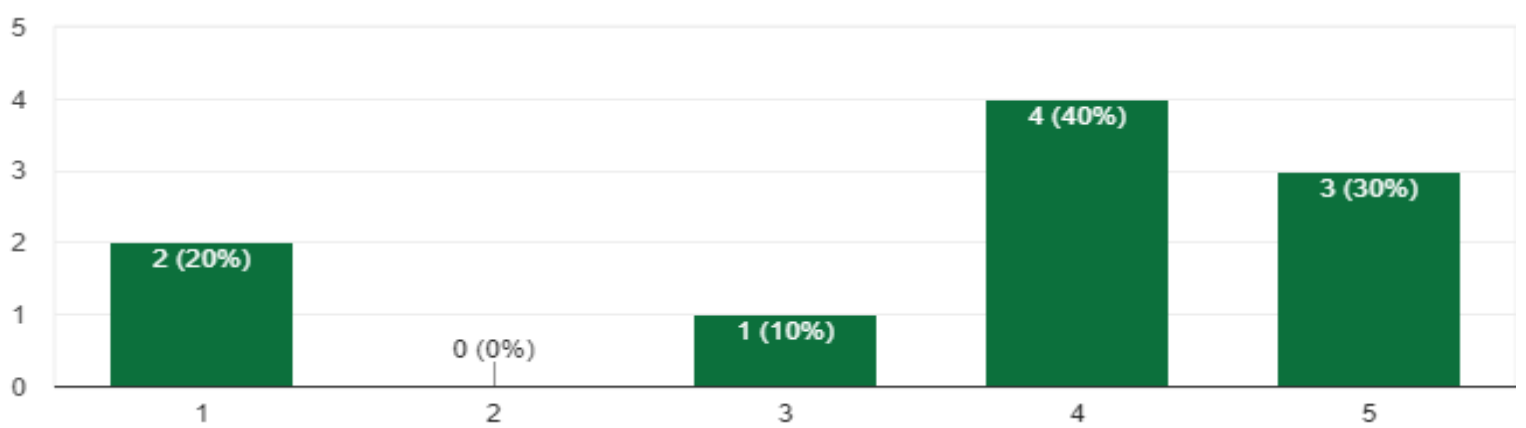

Figura 3. Importância da aplicação de práticas pedagógicas colaborativas nos processos de ensino e aprendizagem na percepção dos participantes da oficina na fase diagnóstico

\section{Lições Aprendidas}

A presente atividade configurou-se em momento de colaboração, engajamento individual e coletivo, interdependência positiva entre os participantes, troca de experiências quanto a prática docente e os desafios na incorporação do uso das TDICs em sala de aula.

Neste sentido, identificamos diferentes níveis de maturidade quanto ao domínio do uso da tecnologia entre os participantes, principalmente no que diz respeito ao manuseio do smartphone enquanto artefato pedagógico. Esse fato prejudicou o progresso no processo de aprendizagem ativa por parte daqueles com pouca experiência, deixando claro que os desafios para utilização das TDICs vão muito além do conhecimento acerca dos recursos e funcionalidades das ferramentas em si.

Outro aspecto relevante foi a dificuldade que alguns apresentaram no desenvolvimento das atividades colaborativas, principalmente pelo hábito de estarem passivos no processo de ensino e aprendizagem. Este fato pode ser ratificado pelo relato de um dos participantes na avaliação de reação que manifestou o seguinte: "Inicialmente percebi a ausência de diagnóstico da turma, pois apesar de estarmos em ascensão tecnológica, ainda existem pessoas na sala de aula que não buscam atualizar suas práticas perante mudanças repentinas nas tecnologias digitais". Apesar da dificuldade de alguns na realização da atividade, Procópio (2011) justifica que formações colaborativas com auxílio de tecnologia podem promover o desenvolvimento profissional dos participantes.

\section{Considerações Finais}

Considera-se que a atividade de formação ministrada em formato de oficina intitulada "Práticas Pedagógicas Colaborativas na formação das habilidades do profissional do futuro" atingiu o objetivo de apresentar ferramentas digitais no apoio a práticas pedagógicas colaborativas, bem como proporcionar mudanças na percepção dos educadores alvo da formação, no que diz respeito aos benefícios das práticas educacionais colaborativas e a utilização das TDICs em sala de aula.

As práticas pedagógicas desenvolvidas em conjunto com as ferramentas digitais apresentadas foram classificadas como recursos pedagógicos importantes pelos participantes da oficina, principalmente pela possibilidade de conciliar com metodologias ativas de Ensino, a exemplo do Design Thinking pelas ferramentas Mentimeter e Coggle; Sala de Aula Invertida e Aprendizagem Colaborativa com auxílio do Google Forms e Docs; Aprendizagem por Pares e TBL com Plickers; Gamificação com Classdojo. 
VII Congresso Brasileiro de Informática na Educação (CBIE 2018)

Anais do XXIV Workshop de Informática na Escola (WIE 2018)

Como trabalho futuro, sugere-se que a presente atividade seja dividida em níveis "Iniciante" e "Avançado"; assim como ofertada em uma carga horária maior, preferencialmente $08 \mathrm{~h}$ ou 16h, para que seja possível fortalecer os conhecimentos, habilidades, atitudes e competências dos participantes na utilização de tais ferramentas digitais em sala de aula.

\section{Referências}

Antunes, M. A. e Barroso, F. (2015) "Tecnologias na Educação: Ferramentas Digitais Facilitadores da Prática Docente", Pesquisa e Debate em Educação, v.5, p.124-131.

Beira, D. G. e Nakamoto, Paula Teixeira. A Formação docente inicial e continuada prepara os Professores para o Uso das Tecnologias de Informação e Comunicação (TICs) em sala de aula?. In: Anais do XXII Workshop de Informática na Escola (WIE 2016), p. 825-834. DOI:10.5753/cbie.wie.2016.825.

Diesel, Aline., Baldez, Alda e Martins, Silvana. (2017) "Os princípios das metodologias ativas de ensino: uma abordagem teórica". Revista Thema, v.14, p.268-288.

Gil, A. C. "Métodos e técnicas de pesquisa social". 5.ed. São Paulo: Atlas.

Oliveira, Gabriela; Kunrath, Nadma Farias; Rocha, Sérgio Antônio Francalino; Silva, Luiz Augusto Matos da. Uso de Dispositivos Móveis como Recurso Didático na Formação Docente. In: Anais do XXIII Workshop de Informática na Escola (WIE 2017), p. 725-734. DOI: 10.5753 /cbie.wie.2017.725.

Procópio, E. R. (2011) "Formação de professores e tecnologias: implicações da educação a distância na prática docente". (Dissertação) Universidade Federal de Juiz de Fora, 139p.

Silva, Maria Auricélia da Silva e Filho, José Aires de Castro. Trabalho Colaborativo com Suporte Digital: uma experiência de formação docente. In: Anais do XXII Workshop de Informática na Escola (WIE 2016), p. 766-775. DOI: 10.5753/cbie.wie.2016.766.

Thiollent, M. (2011) "Metodologia da pesquisa-ação", São Paulo: Cortez Editora.

Vasconcelos, Thiago G.; Souza, Flávia Veloso Costa; Araújo, Ana Liz Souto O.; Rodrigues, Liviany R.; Souza, Ítalo D. de; Sousa, Alayse L. Planejamento e realização de oficina de capacitação de professores das escolas públicas para a inclusão do Tablet Educacional em sala de aula. In: Anais do XXII Workshop de Informática na Escola (WIE 2016), p. 776-785. DOI: 10.5753 /cbie.wie.2016.776.

Vianna, M.; Vianna, Y.; Adler, I.K; Lucena, B; Russo, B. (2012). "Design Thinking: Inovação em Negócios". Rio de Janeiro: MJV Press. 